\title{
David Creech
}

\section{The Use of Scripture in the Apocryphon of John}

\author{
A Diachronic Analysis of the Variant Versions
}

[Die Verwendung der Schrift im Apokryphon des Johannes. Eine diachrone Analyse der verschiedenen Versionen.]

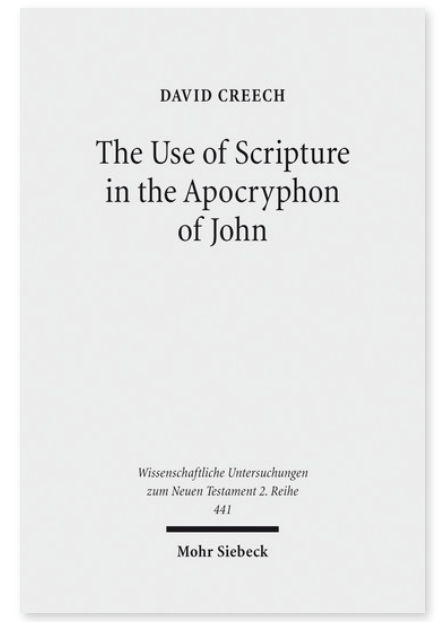

2017. XI, 148 Seiten. WUNT II 441

ISBN 978-3-16-153808-7

DOI 10.1628/978-3-16-153808-7

eBook PDF $64,00 €$

ISBN 978-3-16-152983-2

fadengeheftete Broschur $64,00 €$
Veröffentlicht auf Englisch.

David Creech untersucht die ambivalente Behandlung der jüdischen und der christlichen Schriften im Apokryphon des Johannes. Obwohl Moses an fünf Stellen im Text ausdrücklich korrigiert wird, ist Genesis' Schöpfungsbericht dennoch die Basis von Weltentstehung und Anthropogonie. Die ungleiche Behandlung der biblischen Texte ist das Ergebnis eines Streits zwischen den Autoren des Apokryphon und anderen frühen Katholiken. Im frühesten Stadium des Textes übten die Christen, die den Apokryphon schrieben und lasen, ihre Religion noch neben frühen katholischen Christen aus, ohne ein Gefühl der Widersprüchlichkeit oder Unvereinbarkeit. Der entscheidende Wandel im Apokryphon geschah nach Irenäus von Lyons Angriff auf die »fälschlich sogenannte Erkenntnis«. Als Antwort auf seine gezielten Bemühungen, die Kirche unter die Amtsgewalt früher katholischer Bischöfe zu bringen, fügten die Urheber Korrekturen zu Moses hinzu. Die Korrekturen sind hauptsächlich rhetorischer Natur und entkräfteten die Kennzeichen katholischer Identität.

David Creech Born 1976; 1999 BA; 2002 MDiv; 2011 PhD; 2008-12 Program Director for Hunger Education for ELCA World Hunger; 2012-13 Teaching Fellow at Loyola University Chicago; since 2013 Assistant Professor of Religion at Concordia College, Moorhead.

\section{Jetzt bestellen:}

https://mohrsiebeck.com/buch/the-use-of-scripture-in-the-apocryphon-of-john-9783161538087?no_cache=1 order@mohrsiebeck.com

Telefon: +49 (0)7071-923-17

Telefax: +49 (0)7071-51104 